International Journal of Linguistics, Literature and Culture
Available online at https://sloap.org/journals/index.php/ijllc/
Vol. 7, No. 4, July 2021, pages: $209-221$
ISSN: 2455-8028
https://doi.org/10.21744/ijllc.v7n4.1637

\title{
Implicit Meaning in Surat Yusuf of the Glorious Quran: Pragmatic Perspective
}

Hind Majeed Sallal a Abbas Lutfi Hussein ${ }^{b}$

Article history:

Submitted: 18 March 2021

Revised: 27 April 2021

Accepted: 9 May 2021

\section{Keywords:}

Glorious Qur'an;

implicature;

implicit meaning;

pragmatic inferences;

presupposition;

\begin{abstract}
Implicit meaning is a sort of meaning which is not overtly identified in a communication. This definition gives rise to a problem of fragmentation. Thus, this paper aims to delimit the range of implicit meaning and to shed light on its types and devices utilized to express this meaning, detecting the functions behind the hidden meaning. Applying Larson's (1984) and Verschueren's (1999) approaches, eight extracts are selected from Surat Yusuf to be analyzed in terms of implicit meaning used. The paper concludes that implicit meaning is not a fixed entity; it can be molded and remodeled in the linguistic interaction and consequently its functions vary according to the situation in which they occur. Furthermore, implicit meaning appears to function as focusing on new information, avoiding redundancy and repetition, demanding politeness, suspense and motivation, using ironically and metaphorically, avoiding discomfort, and giving more explanation for the sake of warning or intimacy.
\end{abstract}

International journal of linguistics, literature and culture (C) 2021. This is an open access article under the CC BY-NC-ND license (https://creativecommons.org/licenses/by-nc-nd/4.0/).

Corresponding author:

Hind Majeed Sallal,

Iragi University.

Email address: hindsallal5@gmail.com

${ }^{a}$ Iragi University

${ }^{\mathrm{b}}$ Iragi University 


\title{
1 Introduction
}

Pragmatics combines different sides of language with its users, i.e., addresser, addressee, reader, or writer. Moreover, it discovers the connection between language construction and principles of language use. Overall, it is a discipline that offers a broad interdisciplinary range of issues as a social, psychological, and cultural phenomenon and procedures. Generally speaking, the recent study of pragmatics is greatly affected by the philosopher, Paul Grice, who proposed a "theory of inferences" that the addressee takes to get at a complete understanding of what an addresser meant by an utterance in which what is meant goes beyond what is said.

Thus, the study of implicit meaning becomes the main concern of pragmaticism approaches as it concerns the identification of meaning that underlies what is given by the language $\mathrm{f}$. In other words, the study of implicit meaning involves not only the precise literal meaning of words and sentences, but also aspects of meaning that are related to linguistic performance, intents of interlocutors, shared knowledge of the world and beliefs by speaker and hearer, anticipations of the interlocutors in a particular speech, and other issues emergent from the contextually entrenched action (Abbott, 2000; Dryer, 1996). Hence, the property of speech that could be studied under implicit meaning seems to be an unavoidable subject of investigation.

\section{Explicitness and implicitness}

There is a general agreement among linguists that in every communication two parts of meaning are inevitable: explicit and implicit. Verschuren (1999), Croft (2000); Cruse (2000), Kearns (2000), and Roberts (2005), confirm that the impossibility of complete explicitness is because when people talk about something; "the amount of information included in the text will depend on the amount of shared knowledge" that is already known to the addressee. Stubbs (1983), regard implicating some sort of information as a logical way of recognizing a text that is characterized by cohesion, continuity, and grouping. According to Verschuren (1999), what can be applied to spoken discourse is equally true for writing as proposed in the following:

\begin{abstract}
"Though written texts form a medium which necessitates Certain types of explicit formulation because producer and interpreter usually do not share the same time and space, nor in many cases a joint communicative purpose, they carry along an equal amount of unexpressed information which is assumed to be known."
\end{abstract}

Verschuren (ibid) considers explicit meaning simply as a representation of implicit forms of meaning to achieve a full understanding of any example of language use, explicit aspects of general background information are needed. For instance, 'The center is closed in January' requires a sort of specification of which 'center' it is the one the speaker talks about and whether the month January is meant to be a January of a specific year or every year, etc. So, such a need helps interlocutors to avoid misunderstandings (Muhaimi \& Nawawi, 2016).

\section{Implicit Meaning and Indirectness}

Whenever interlocutors speak, they have some intentions in speaking. Sometimes the intention is implicit, so it is not conveyed directly by the utterance produced. Cruse (2000) and Lyons (1977), point out that the notion of implicit meaning rests upon a distinction between what is said and what is implied in saying what is said. For Smith \& Wilson (1979), understanding the tacit meaning of an utterance requires a system of knowledge and inferences to move from overt reply to implicit message. Consider the following examples:

(1) A: Where's my box of chocolate? B: Where are the snows of yesterday?

(2) A: Where's my box of chocolate? B: Where's your diet sheet?

(3) A: Where's my box of chocolate? B: The children were in your room this morning.

Intuitively, it is clear what is going on. B's reply in (1 A) is not a direct response to A's question. However, B's answer would convey an indirect response that his box of chocolate was gone. Similarly, less direct responses to the 
same question are conveyed in (2B) and (3B).

Smith and Wilson (ibid), influenced by Paul Grice's influential lectures, affirm the crucial role played by judgments of relevance in the interpretation of utterances. That is, a hearer will attempt to get out a remark just what he believes the addresser put into it, then his judgment about the implicit intended message will mainly affect the amount of indirect message, thus he is prepared to do to get implicit meaning out of it. Moreover, according to Akmajian et al. (2017), "the indirect acts can be performed employing either literal or non-literal indirect acts". Consider the following examples:

\section{(4) a- "You're the boss" (agreeing what the hearer articulates). b- "I should never have done that" (expressing apology).}

The two points $(4 \mathrm{a} \& 4 \mathrm{~b})$ are examples of indirect acts, executed via literal direct acts in which the addresser means what is said, besides what is meant. Thus, for the hearer to find the speaker's indirect implicit intent of what is said, both the context and conversation presumptions are necessary to be taken into consideration. In other words, the first thing to notice is that what is said would be contextually unsuitable for the speaker to be speaking only straightforwardly.

For Leech (1983), Yule (1996), and Saeed (1997), implicit meaning is that sort of meaning which is in the mind of the addresser when he is performing his message. Since it is in the mind of the addresser, it is reasonable to conceive what is meant by taking the context of the situation into account. Bloom \& Lahey (1978), adds that there are different sets of circumstances that determine how a speaker might use language to accomplish the same goal, for instance, who the listener is, what the addresser knows about the addressee, their relationship, and situation of context.

\section{Implicit meaning and reflexive intention}

The function of language is often said to communicate information. However, Keller (cited in Croft, 2000) argues that communication, which is a transfer of information, is not just a transfer of information. That is, a speaker usually transfers implicitly more information he intends to convey. In this respect, Searle (1969), cited in Leech (1983) states:

\footnotetext{
"In speaking, I attempt to communicate certain things to my hearer by getting him to recognize my intention to communicate just those things I achieve the intended effect on the hearer by getting him to recognize my intention to achieve that effect."
}

Hence, the function of language is some extralinguistic goal of the speaker like being socially successful and influencing others employing language. Additionally, such function of language is not carried unless both the addresser and addressee act jointly in an activity. This reflexive intention is achieved by what Bach \& Harnish (1979), call 'the communicative presumption', i.e., the mutual belief shared by the presumption, i.e., the mutual belief shared by interlocutors. Thus, the hearer must be able to identify the propositional act that is presented implicitly by the speaker, otherwise, the speech act would not be completely successful. Van Dijk (1998) and Tyler (1978), point out that although speakers and hearers frequently have different shared knowledge for the same utterance which is the source of many disagreements and much misunderstanding, they may still understand each other as long as they assume agreement in their mutual knowledge. So, communication, as viewed by Levinson (1983), "is a complex kind of intention that is achieved or satisfied just by being recognized".

\section{Larson and Verschueren's implicit meaning}

According to Larson (1984), implicit meaning is classified into referential implicit meaning, organizational implicit meaning, and situational implicit meaning. By referential implicit meaning, Larson refers to the referential meaning of words and sentences which is organized into a semantic structure. Thus, it concerns "a certain thing, event, attribution or relation" which interlocutors can perceive or imagine, besides a thing which "happened or may happen or is imagined as happening". For instance, if someone inquires "How many people came" and then someone answers Ten, then it means in this situation that Ten refers "Ten people came", and hence, "the reference to people and came is left implicit". Consequently, "leaving some information implicit is one feature to signal organizational

Sallal, H. M., \& Hussein, A. L.. (2021). The Implicit Meaning in Surat Yusuf of the Glorious Quran: Pragmatic Perspective. International Journal of Linguistics, Literature and Culture, 7(4), 209-221. https://doi.org/10.21744/ijllc.v7n4.1637) 
meaning". The implicit type of meaning is associated with "grammar to indicate old information to add cohesion."

Larson (ibid: 41) adds that less explicit structures are manipulated to indicate "organizational meaning", e.g. pronouns, pro-verbs, and "other substitute words are less explicit" than the verbs and nouns. The last type of Larson's is situational implicit meaning between interlocutors in the context of the situation in which many situational matters result in situational meaning as where and when the communication takes place, the age, sex, and social relation between interlocutors. The importance of Larson's types of implicit meaning in this study lies in illustrating some general ways of understanding implicitness of meaning.

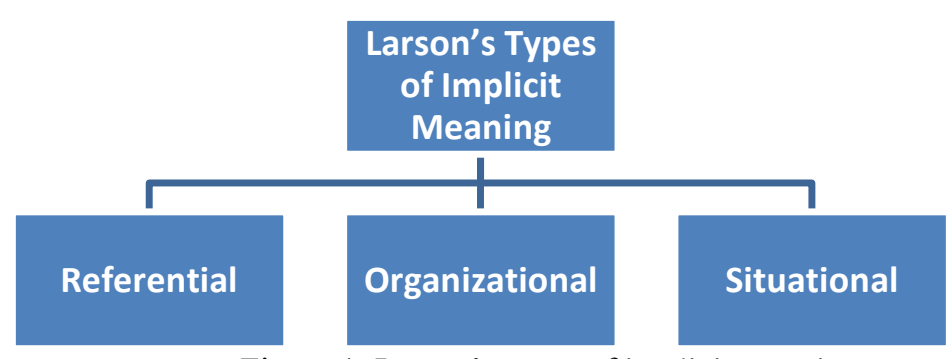

Figure 1. Larson's types of implicit meaning

On the other hand, Verschueren classifies implicit meaning as the following:

1) Presupposition implicit meaning already known and understood to make sense.

2) Conventional implicature (logical implication), reasonably deduced from a "form of expression".

3) "Standard conversational implicature", conventionally deduced from "forms of expression in combination with conversational maxims".

4) "Non-conventional implicature or occasion-specific implicit meaning", deduced from the clear "flouting of a conversational maxim in combination with the co-operative principle".

Verschueren's types of implicit meaning presented in this study are significant as conventionalized and inferential carriers of implicit meaning, i.e., tools for linking explicit content to relevant aspects of shared knowledge and hence as tools for Larson's types of implicit meaning representation.

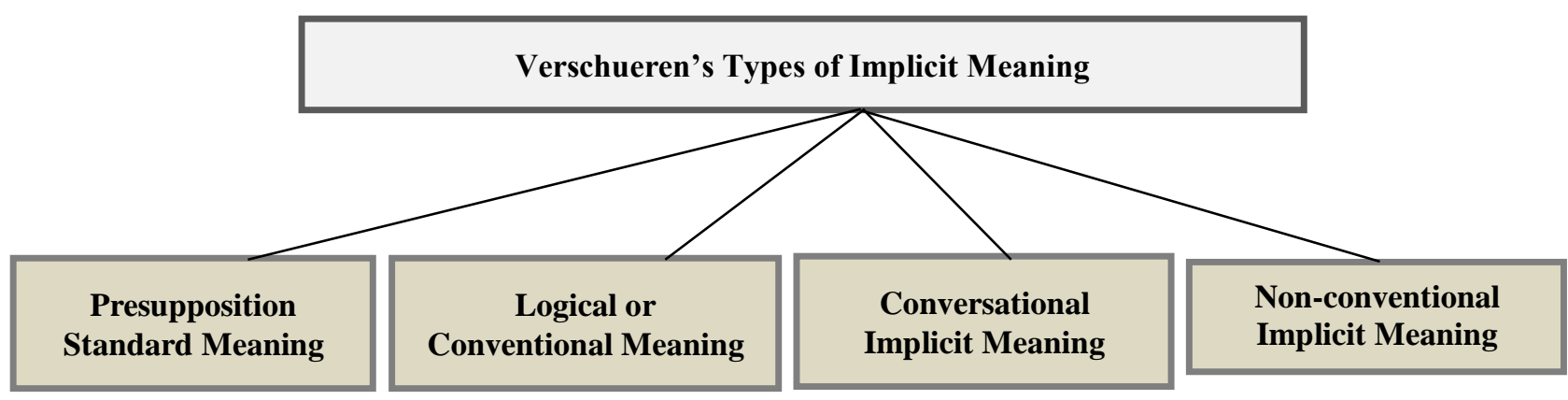

Figure 2. Verschueren types of implicit meaning

\section{Materials and Methods}

The main argument in this study is that Larson's communicative model and Verschueren's inferential model of implicit meaning require pragmatic analysis and cognitive description which is crucial to the understanding of implicit meaning in Surat Yusuf of the Glorious Quran. Three stages of comprehension as an integral communicative approach invented by the researchers are necessary for the analysis of implicit meaning. 


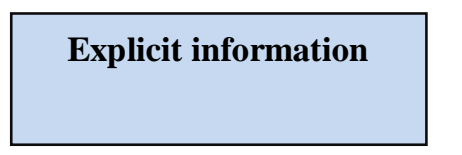

Stage (1)

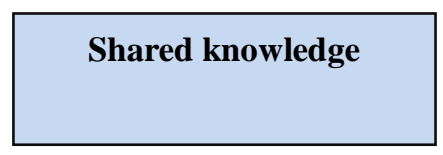

Stage (2)
Pragmatic inferences

$+$

Stage (3)

Figure 3. Integral communicative approach of implicit meaning

1) The first stage is (explicit information) involves understanding the explicit meaning of an utterance which is specified by vocabulary and grammatical forms, i.e., a body of linguistic knowledge.

2) The second stage (shared knowledge) involves all the available facts about the world known to participants as previous conversations, social and cultural background shared knowledge, common experiences, place, time and age, etc.

3) The third stage (pragmatic inferences) involves understanding the reflexive intentions (i.e. speaker and hearer communicative message), conventional implicature (those implications which can be drawn from the conventional meaning of the words in combination with conversational maxims), and conversational implications (those implications which arise not from conventional meaning but general features of discourse deduced from "the flouting of a conversational maxim" in association with "co-operative principles").

Given these stages, implicit meaning communicative content of an utterance can be deductible from all the inferences that can be made or deducible from (a) what is said (the sentence uttered by purely linguistic and semantic rules), (b) from non-linguistic knowledge shared by the addresser and addressee. The devices used for the occurrence of implicit meaning in certain utterances are deletion through the use of elliptical sentences and concise words (words that carry a lot of information) and the use of periphrases. The data is selected from the story of Prophet Yusuf of the Glorious Quran, as shown in the following sections.

\section{Results and Discussions}

\section{Example 1}

$$
\text { " اذ قال يوسف لابيه يا ابت اني رايت احد عثر كوكبا والثمس والقمر رايتهم لي ساجدين"(4) (سورة يوسف الآية4 ) }
$$

4- "Behold, Joseph said to his father "O my father I did see eleven stars and the sun and the moon: I saw them prostrate themselves to me!”. Surah Yusuf 4 (Yusuf, 2001:229)

1- Type of implicit meaning used: referential implicit meaning in (his father)

Tool used: presupposition

Strategy used: non-literal direct

Implicit meaning proposition deducibility: explicit representation and shared knowledge

Device used: deletion of word (son)

Function: focus on new information.

2- Type of implicit meaning used: situational implicit meaning in (I did see)

Tool used: conventional implicature

Strategy used: non-literal direct

Implicit meaning proposition deducibility: pragmatic inference

Device used: concision in (see)

Function: informativeness and suspense motivation.

3- Type of implicit meaning used: referential implicit meaning in (the sun \& the moon)

Tool used: presupposition

Strategy used: non-literal direct

Sallal, H. M., \& Hussein, A. L. (2021). The Implicit Meaning in Surat Yusuf of the Glorious Quran: Pragmatic Perspective. International Journal of Linguistics, Literature and Culture, 7(4), 209-221.

https://doi.org/10.21744/ijllc.v7n4.1637) 
Implicit meaning proposition deducibility: explicit representation and shared knowledge

Device used: deletion of word (definite \& known)

Function: focus on new information.

4- Type of implicit meaning used: organizational implicit meaning in (I saw them)

Tool used: presupposition

Strategy used: non-literal direct

Implicit meaning proposition deducibility: explicit representation and shared knowledge

Device used: deletion of word (eleven stars and the sun and the moon)

Function: for emphases and avoiding repetition\& redundancy.

5- Type of implicit meaning used: situational implicit meaning in (the whole exchange)

Tool used: conversational implicature (violating of a maxim )

Strategy used: non-literal direct

Implicit meaning proposition deducibility: pragmatic inference

Device used: deletion of sentence (question)

Function: informativeness and politeness.

The story of Prophet Joseph begins with this exchange between the son Joseph and the father Jacob without any introduction and details, the thing that sheds light upon the main event in the story. Different types of implicit meaning are recognized. The first one is referential implicit meaning through the use of the words his father (لابيه). This indicates that the relation between the speaker and the hearer is an intimate relation of father and son and the tool used to arrive at this type is a presupposition, whereas the device used is concision and the function of this implicit meaning is to focus on new information that Joseph's father is still alive and keep on listening to his son.

Another referential implicit meaning is in the words (the sun and the moon) through the use of presupposition since they are definite and already crystal clear to everybody. Consequently, focusing on what Jacob knows as having an image in his mind, Prophet Joseph builds the new information that eleven stars beside the sun and the moon, as already shared background knowledge, make obeisance to him. Moreover, organizational implicit meaning also appears when Joseph refuses the words 'I did see them' (رايته) in which he attempts to emphasize to his father seeing the eleven stars beside the sun and the moon as well as avoiding repetition and redundancy through deletion.

One more type is situational implicit meaning, made through the use of conventional implicature deducible from pragmatic inferences via the use of concision. It is indicated when Prophet Joseph said "I did see eleven stars, the sun and the moon" which implicates the real and unreal seeing since the story began without any preface that thing that leads the reader to expect and infer that one of the two options can happen since the speaker is a Prophet who is the son of a Prophet. The element of suspense and motivation is the reason behind implicating this information that it is a vision that is so clear in the next Aaya (Qur'anic verse). Another situational implicit meaning is revealed through the use of conversational implicature that Prophet Joseph makes an indirect request asking his father to explain what the meaning of his vision is and by that he violates the maxims of quantity. The device used is concision and the function is for the demand of politeness.

\section{Example 2}

$$
\text { " قال يا بني لا تقصص روئك على اخوتك فيكيدوا للك كيدا ان الثيطان للانسان عدو مبين"(5) (سورة يو سف الآية5 ) }
$$

5- "Said (the father): My (dear) little son! Relate not thy vision to the brothers. Lest they concoct a plot against thee: for Satan is to man avowed enemy!" Surah Yusuf 4 (Yusuf, 2001).

1- Type of implicit meaning used: referential implicit meaning in (little son)

Tool used: presupposition

Strategy used: non-literal direct

Implicit meaning proposition deducibility: explicit representation and shared knowledge

Device used: deletion of word (father)

Function: focus on new information.

2- Type of implicit meaning used: organizational implicit meaning in (do not relate your vision) 
Tool used: presupposition

Strategy used: non-literal direct

Implicit meaning proposition deducibility: explicit representation and shared knowledge

Device used: deletion of words (eleven stars and the sun and the moon prone themselves to him)

Function: avoiding repetition\& redundancy.

3- Type of implicit meaning used: situational implicit meaning in (to your brothers)

Tool used: presupposition

Strategy used: non-literal direct

Implicit meaning proposition deducibility: pragmatic inference

Device used: deletion of words (eleven brothers)

Function: focus on new information.

4- Type of implicit meaning used: situational implicit meaning in (lest they devise a plan against you)

Tool used: conversational implicature (violation of maxim)

Strategy used: non-literal non-direct

Implicit meaning proposition deducibility: pragmatic inference

Device used: concision in (they devise a plan against you)

Function: warning.

5- Type of implicit meaning used: situational implicit meaning in (the Satan is an enemy to man)

Tool used: conversational implicature (flouts of maxim)

Strategy used: non-literal non-direct

Implicit meaning proposition deducibility: pragmatic inference

Device used: concision in (the Satan is an enemy to man)

Function: emphasis\& justification \& informativeness.

When Jacob tells his son that he must not tell the vision to his brothers, referential and organizational implicit meanings are revealed that the relation between the addresser and addressee is a strong relation of father and son (Wakusawa et al., 2007; Shapira-Lishchinsky, 2019). The device used is deletion which is remarkable by the use of presupposition to focus on what is more important. And by avoiding repetition and redundancy which is so clear, the words (your vision) refer to Joseph's seeing of eleven stars and the sun and moon as creating deference to him. Considering the situational implicit meaning through presupposition, and by using deletion the father refers to Joseph's brothers who are eleven but not from the same mother except Benjamin.

This implicit information is background shared knowledge deducible from pragmatic inferences that his sons do not like their brother Joseph and may envy him, the thing may lead them to devise a plan against him (Breheny et al., 2006; Goodman \& Frank, 2016). Moreover, another pragmatic inference can be made that the father instead of explaining the vision to his son, orders him not to tell it to his brothers, and by that, the father violates the maxim of relevance. Consequently, the function of such implicating is to warn his son from his brothers to keep him safe. Besides all in justifying the reason behind their hatred, the father again flouts the maxim of relevance emphasizing the informative idea that his brothers' plan against him if it would happen it is just because of Satan who is an open enemy to man. This pragmatic inference of justification indicates that the reason behind that is to prevent Joseph from having rancor in his heart and mind towards his brothers. Joseph's father flouts another maxim which is of quantity since he does not tell him the reasons behind this warning which is going to be so obvious later on in the story.

\section{Example 3}

" اقتلوا يوسف او اطرحوه ارضا يخل لكم وجه (بيكم وتكونوا من بعده قوما صالحين(9) قال قائل منهم لا تقتلوا يوسف والقوه في غيبت الجب يلتقطه

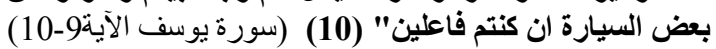

9- "Slay ye or cast him out to some (unknown)land, that so the favour of your father may be given to you alone:(there will be time enough) for you to be righteous after that!

10-Said one of them "slay not Joseph, but it ye must do something, throw him down to the bottom of the well: he will be picked up by some caravan of travelers.” Surah Yusuf 9-10 (Yusuf, 2001:230).

Sallal, H. M., \& Hussein, A. L.. (2021). The Implicit Meaning in Surat Yusuf of the Glorious Quran: Pragmatic Perspective. International Journal of Linguistics, Literature and Culture, 7(4), 209-221. https://doi.org/10.21744/ijllc.v7n4.1637) 
1-Type of implicit meaning used: situational implicit meaning in the whole example

Tool used: conventional implicature

Strategy used: non-literal direct

Implicit meaning proposition deducibility: pragmatic inference

Device used: deletion of words (Joseph's brother hatred and their disagreement to choose any option to get ridge of him)

Function: suspense and informativeness

Arousing three different opinions as a plan against Joseph indicates that his brothers aimed at getting rid of him which also reflects their feelings of dislike and hatred towards him. The reason behind this is simply because he and his brother Benjamin are more adorable than them by their father as they claimed previously in the aaya. This implicit knowledge is pragmatically inferred as a situational implicit meaning through the use of conventional implicature by deletion. Moreover, their ideas of how to get rid of Joseph are not agreed upon as a final decision and are rejected by one of them but he is obliged to submit to the opinion of the majority to throw him down to the bottom of the well. The function of this implicit situation meaning is to stimulate the element of informativeness and suspense about what they finally intend to do with their little brother and what they may carry to their poor father as a justification for their bad deed.

\section{Example 4}

$$
\text { " قالوا يا ابانا ما للك لا تامنا على يوسف وال لله لناصحون"(11) (سورة يوسف الآية11 ) }
$$

11- They said "O our father! Why dost thou not trust us with Joseph-seeing we are indeed his sincere wellwishers?" Surah Yusuf 4 (Yusuf, 2001).

1- Type of implicit meaning used: situational implicit meaning in (do not trust us)

Tool used: presupposition

Strategy used: non-literal direct

Implicit meaning proposition deducibility: explicit representation and shared knowledge

Device used: concision in (do not trust us)

Function: persuasion and earning trust.

2- Type of implicit meaning used: situational implicit meaning in (do not trust us)

Tool used: conversational implicature (flouts of maxim)

Strategy used: non-literal non-direct

Implicit meaning proposition deducibility: pragmatic inference

Device used: deletion of lack of trust

Function: emphasis\& justification, informativeness and persuasion.

After setting an agreement about how to get rid of Joseph and finding a justification to do that, they began to carry out their plotted plan. Situational implicit meaning is recognized through the use of presupposition as a tool using concise words ( لا لامنا do not trust us) which carry a lot of implicit information that can be inferred pragmatically. Thus, the words imply that the relation between Jacob and his sons concerning Joseph is a relation of mistrust and uncertainty. Besides, it also implies that they might try more than once to single out Joseph and their father prevented them from doing so. Jacob's feeling of insecurity and fear make them realize that they are not trusted by their father concerning Joseph, the thing that leads them to flout the maxim of quality pretending that they are saying the truth and can be trusted while the opposite is true for their insistence to harm their brother awfully. Emphasis, justification, informativeness, and persuasion are used in this example as a function for this use of implicit meaning.

\section{Example 5}

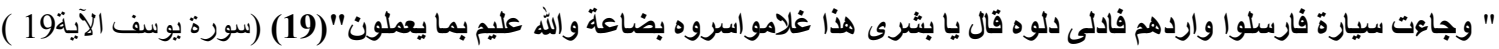
19- "Then there came a caravan of travelers: they sent their water carrier (for water), and he let down his bucket (into the well)...He said “Ah there!Good news! Here is a (fine) young man!” so they concealed him as a treasure! 
But Allah knoweth well all that they do!" (Yusuf, 2001).

1-Type of implicit meaning used: organizational implicit meaning in (travelers' water carrier)

Tool used: presupposition

Strategy used: non-literal direct

Implicit meaning proposition deducibility: explicit representation and shared knowledge

Device used: deletion of the sentence (travelers had a water carrier)

Function: focus on new information

2- Type of implicit meaning used: situational implicit meaning in (travelers sent their water carrier who let down his bucket)

Tool used: conventional implicature

Strategy used: non-literal non-direct

Implicit meaning proposition deducibility: pragmatic inference

Device used: deletion of the sentence (the water carrier listened to their order and went to the well as he already knew the place of the well)

Function: to be brief through avoiding detailed long narrative.

3- Type of implicit meaning used: referential implicit meaning in (her is a fine young man)

Tool used: presupposition

Strategy used: non-literal non-direct

Implicit meaning proposition deducibility: explicit representation and shared knowledge

Device used: concision in (young man)

Function: emphasis that he was unknown to them.

4- Type of implicit meaning used: organizational implicit meaning in (travelers concealed him)

Tool used: presupposition

Strategy used: non-literal non- direct

Implicit meaning proposition deducibility: explicit representation and shared knowledge

Device used: deletion of the sentence (they concealed the young boy)

Function: reflecting the feeling of happiness as they found a slave which means money to them.

In this example, Allah (the almighty) describes how some caravan travelers picked Joseph up the well in a very wonderful briefness. Therefore, it requires implicating sentences through deletion and concision. Organizational implicit meaning appears to be in the words (فارسلوا) they send their water carrier) through the use of presupposition depending on the shared knowledge that the caravan travelers have a water carrier who is sent to fetch water. Another situational implicit meaning shows that their water carrier obeys their order and does what is required from him. Moreover, through pragmatic inference, the caravan travelers seem to know the place well since they direct their water carrier to its place without serious trouble or difficulty. Implicit meaning additionally recognized in so they concealed him as a treasure) in which it seems that they are slave traders who used to buy and sell slaves at that time. Here an emphasis is placed on the idea that he was unknown to them and also they did not want others to know him and then to lose him, therefore they concealed him as a treasure. Consequently, the function behind this use is to show their feeling of happiness for they found the precious thing that can benefit all of them.

\section{Example 6}

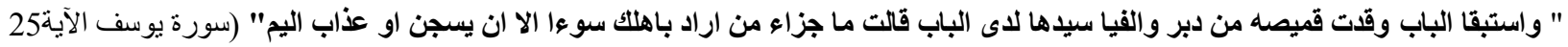

25- "So they both raced each other to the door, and she tore his shirt from the back: they both found her lord near the door. She said: "what is the fitting punishment for one who formed an evil design against thy wife, but prison or a grievous chastisement.” (Yusuf, 2001:232).

Sallal, H. M., \& Hussein, A. L. (2021). The Implicit Meaning in Surat Yusuf of the Glorious Quran: Pragmatic Perspective. International Journal of Linguistics, Literature and Culture, 7(4), 209-221. https://doi.org/10.21744/ijllc.v7n4.1637) 
1- Type of implicit meaning used: referential implicit meaning in (they both raced each other to the door)

Tool used: presupposition

Strategy used: non-literal direct

Implicit meaning proposition deducibility: explicit representation and shared knowledge

Device used: deletion of the sentence (Joseph and the chief's wife hastened to the door)

Function: focus on new information.

2- Type of implicit meaning used: situational implicit meaning in (what is the fitting punishment for one who intends evil to your wife)

Tool used: conversational implicature (flout of maxim)

Strategy used: non-literal non-direct

Implicit meaning proposition deducibility: pragmatic inference

Device used: concision in (intends evil to your wife)

Function: suspense and remove doubt.

Through the use of presupposition, a certain type of shared knowledge is applied that Joseph and the chief's wife who took care of him when he was a little young boy, are both hastened to the door. Although she tried as much as possible to catch him, he runs away from her and then they met her husband at the door. In attempting to justify the situation to her husband, she flouts the maxim of quality telling a lie that Joseph is the one who intends evil to her while the opposite is that she is the indecent one. Another pragmatic inference indicates that she is more powerful than her husband since she orders him indirectly not only to punish Joseph but additionally she limits the ways of his punishment by either imprisonment or a painful chastisement as a means of torturing Joseph for not obeying her.

\section{Example 7}

" وقال نسوة في المدينة امراة العزيز تراود فتاها عن نفسه قد شغفها حبا انا لنراها في ظلال مبين"(30 (30) (سورة يوسف الآية 30 ) ) 30- Ladies said in the city: "The wife of the (great) Aziz is seeking to seduce her slave truly hath the inspired her with violent love: :we see she is evidently going astray. (Yusuf, 2001).

1- Type of implicit meaning used: referential implicit meaning in (ladies said...)

Tool used: presupposition

Strategy used: non-literal direct

Implicit meaning proposition deducibility: explicit representation and shared knowledge

Device used: deletion of the sentence (unknown few ladies)

Function: show the social rank of the women

2- Type of implicit meaning used: organizational implicit meaning in (her slave)

Tool used: presupposition

Strategy used: non-literal non- direct

Implicit meaning proposition deducibility: explicit representation and shared knowledge

Device used: deletion of the words (Aziz has a wife and she has a slave boy)

Function: limiting the spread of news

In this example, referential and organizational implicit meanings are recognized through the use of presupposition sharing the information that few but not many ladies who are unknown and less in rank than Al-Aziz's wife were blamed her for seducing her slave through the use of deletion. Moreover, the few numbers of the women enable her to invite them to her palace, otherwise, she cannot. Al-Aziz's wife gained her prestigious rank in the city because of her great husband and this implicates the reason behind blaming her for the ladies. Another reason behind deserving the blame is that to seduce her slave whom she brought up as a son.

\section{Example 8}

" وقال الملك ائتوني باه فلما جاء الرسول قال ارجع الى ربك فسئله ما بال النسوة التي قطعن ايديهن ان ربي بكيدهن عليم "(50) (سورة يوسف 
30- So the king said: "bring ye him unto me. But when the messenger came to him, (Joseph) said: "Go thou back to thy lord, and ask him, "what was the matter with the ladies who cut their hands? For my lord is certainly well aware of their snare". (Yusuf, 2001).

1- Type of implicit meaning used: organizational implicit meaning in (send him to me)

Tool used: presupposition

Strategy used: non-literal direct

Implicit meaning proposition deducibility: explicit representation and shared knowledge

Device used: deletion of the words (Joseph, the king and go back to your Lord)

Function: focus on new information.

2- Type of implicit meaning used: situational implicit meaning in (when the messenger came to him)

Tool used: conventional implicature

Strategy used: non-literal non-direct

Implicit meaning proposition deducibility: pragmatic inference

Device used: deletion of the sentence (that the king orders the messenger to go to Joseph and to bring him to the king and the messenger obeyed the king's order and so went to fetch him out of the jail)

Function: to infer meaning and to enjoy understanding it.

3- Type of implicit meaning used: referential implicit meaning in (what are the matter with the ladies who cut their hands)

Tool used: presupposition

Strategy used: non-literal non-direct

Implicit meaning proposition deducibility: explicit representation and shared knowledge

Device used: deletion of the sentences about the story of the woman with the chief's wife invitation to them and how they cut their hands.

Function: avoid redundancy and repetition.

When the king of Egypt saw the vision in which "seven fat cows were being eaten by seven lean ones and seven green ears of corn and other dry", he asked his nobles, men of power and knowledge in the kingdom to interpret the vision for him if they can do. However, they didn't say that it was just a dream without meaning, and the one who was released remembered after the time Joseph declared that he will inform the king of its interpretation. Joseph not only explained the meaning of the vision but also gave them solutions to the problem that they were about to face. Consequently, the king ordered to bring Joseph to him. Referential, organizational, and situational implicit meaning is obvious through the use of deletion to void repletion and focus on new information depending on the already shared information that it was Joseph whom the king asked to fetch to him and also in referring to the story of the women who cut their fingers by knives as they were cutting the fruits as soon as they saw Joseph in the palace of AlAziz's wife.

Regarding the situation, another implicit meaning is understood that when the king orders to bring Joseph to him from the prison, the messenger obeyed the order and went to bring him and sequentially came to Joseph and told him about the desire of the king. So all of these sentences are deleted and understood easily as pragmatic inferences the thing that makes the story so understood and enjoyable at the same time. Moreover, Joseph's refusal to go with the messenger implicates that he wants his innocence more than merely his freedom and being out of the prison despite his ability to exploit the situation and this can't happen unless the king knows the story of the women with the chief's wife as a guide to know the truth.

\section{Conclusion}

The analysis of implicit meaning in the story of Joseph reveals that implicit meaning is not a fixed entity because it depends on the individual language and intentions. Since implicit meaning is not fixed, it can be modeled and remodeled in the course of linguistic interaction and consequently its functions vary according to the situation in which they occur. Pragmatically, implicit meaning shows the beauty of performing and displaying ideas and

Sallal, H. M., \& Hussein, A. L. (2021). The Implicit Meaning in Surat Yusuf of the Glorious Quran: Pragmatic Perspective. International Journal of Linguistics, Literature and Culture, 7(4), 209-221. https://doi.org/10.21744/ijllc.v7n4.1637) 
information. It is partly drawn from the literal or conventional meaning of an utterance formed in a particular context which is shared by interlocutors and depends on the recognition by them of the cooperative principle and its maxims through the use of pragmatic inferences which are the creation of sensible behavior between cooperative participants. Throughout the analysis whenever referential and organizational implicit meaning types are used, presupposition appears to be the tool used and deletion is almost the device for its occurrence. Here, the implicit meaning functions as focusing on new information, avoiding redundancy and repetition, showing the social rank, and limiting the spread of news. Situational implicit meaning type is applied through the use of conventional and conversational implicature involving the use of deletion and concision. In this type implicit meaning serves the purpose of informativeness and demand of politeness, suspense, and motivation, avoiding discomfort and giving an explanation for the sake of warning or intimacy, for emphasis and justification, persuasion and earning trust, briefness through avoiding detailed long narrative, reflecting feelings of emotions, removing doubt and enjoying the comprehend of hidden meaning.

\section{Conflict of interest statement}

The authors declared that they have no competing interests.

Statement of authorship

The authors have a responsibility for the conception and design of the study. The authors have approved the final article.

\section{Acknowledgments}

We are grateful to two anonymous reviewers for their valuable comments on the earlier version of this paper. 


\section{References}

Abbott, B. (2000). Presuppositions as nonassertions. Journal of pragmatics,32(10), 1419-1437. https://doi.org/10.1016/S0378-2166(99)00108-3

Akmajian, A., Farmer, A. K., Bickmore, L., Demers, R. A., \& Harnish, R. M. (2017). Linguistics: An introduction to language and communication. MIT press.

Bach, K., \& Harnish, R. M. (1979). Linguistic communication and speech acts.

Bloom, L., \& Lahey, M. (1978). Language development and language disorders.

Breheny, R., Katsos, N., \& Williams, J. (2006). Are generalised scalar implicatures generated by default? An on-line investigation into the role of context in generating pragmatic inferences. Cognition, 100(3), 434-463. https://doi.org/10.1016/j.cognition.2005.07.003

Burton-Roberts, N. (2005). Robyn Carston on semantics, pragmatics and'encoding'. Journal of linguistics, 41(2), 389-407.

Croft, W. (2000). Explaining language change: An evolutionary approach. Pearson Education.

Cruse, D. A. (2000). Meaning in language: An introduction to Semantics and Pragmatics. Oxford: Oxford University Press.

Dryer, M. S. (1996). Focus, pragmatic presupposition, and activated propositions. Journal of pragmatics, 26(4), 475523. https://doi.org/10.1016/0378-2166(95)00059-3

Goodman, N. D., \& Frank, M. C. (2016). Pragmatic language interpretation as probabilistic inference. Trends in cognitive sciences, 20(11), 818-829. https://doi.org/10.1016/j.tics.2016.08.005

Kearns, K. (2000). Definite Descriptions. Modern Linguistics Series: Semantics. London: Macmillan Press Limited.

Larson, M. L. (1984). Meaning-based translation: A guide to cross-language equivalence (Vol. 366). Lanham, MD: University press of America.

Leech, G. (1983). Principles of Pragmatics, New York: Longman Group Limited.

Levinson, S. C. (1983). Pragmatics Cambridge University Press. Cambridge UK.

Lyons, J. (1977). Semantics. Volume I. Cambridge UP, Cambridge.

Muhaimi, L., \& Nawawi, N. (2016). Textual Representation of Identity in Classroom Discourse. International Journal of Linguistics, Literature and Culture, 4(6), 53-62.

Saeed, J. I. (1997). Cognitive Semantics.

Searle, J. R. (1969). How to derive 'ought'from 'is'. In The is-ought question (pp. 120-134). Palgrave Macmillan, London.

Shapira-Lishchinsky, O. (2019). The implicit meaning of TIMSS: Exploring ethics in teachers' practice. Teaching and Teacher Education, 79, 188-197. https://doi.org/10.1016/j.tate.2018.12.013

Smith, N., \& Wilson, D. (1979). Modern linguistics: The results of Chomsky's revolution (Vol. 255). Midland Books.

Stubbs, M. (1983). Discourse analysis: The sociolinguistic analysis of natural language (Vol. 4). University of Chicago Press.

Tyler, S. A. (1978). The Said and the Unsaid Mind, Meaning, and Culture.

Van Dijk, T. A. (1998). Ideology: A multidisciplinary approach. Sage.

Verschueren, J., \& Verschueren, J. (1999). Understanding pragmatics. Oxford University Press.

Wakusawa, K., Sugiura, M., Sassa, Y., Jeong, H., Horie, K., Sato, S., ... \& Kawashima, R. (2007). Comprehension of implicit meanings in social situations involving irony: A functional MRI study. NeuroImage, 37(4), 1417-1426. https://doi.org/10.1016/j.neuroimage.2007.06.013

Yule, G. (1996). Pragmatics, Oxford: Oxford University Press.

Yusuf, A. (2001). Holy Qur'an: Transliteration in Roman Script with Arabic Text and English Translation. Islamabad: Research Institute, International Islamic University.

Sallal, H. M., \& Hussein, A. L.. (2021). The Implicit Meaning in Surat Yusuf of the Glorious Quran: Pragmatic Perspective. International Journal of Linguistics, Literature and Culture, 7(4), 209-221. https://doi.org/10.21744/ijllc.v7n4.1637) 